\title{
sciendo
}

\section{The Effect of Inspiratory Muscle Training on the Pulmonary Function in Mixed Martial Arts and Kickboxing Athletes}

\author{
by \\ Nasim Alnuman ${ }^{1}$, Ahmad Alshamasneh ${ }^{1}$
}

Inspiratory muscle training (IMT) has found its way into athletes' routine as a promising way of improving pulmonary function in combination with standard training. The objective of the study was to examine the effects of resistive IMT on the pulmonary function variables in athletes of two combat sports, i.e., mixed martial arts (MMA) and kickboxing. Fourteen kickboxing and $12 \mathrm{MMA}$ male athletes qualified for the study. They were randomly assigned into experimental and control groups. While both groups participated in their standard training, the experimental group additionally participated in IMT which consisted of 30 breaths twice a day for 6 weeks. The pulmonary functions were measured at baseline and after 6 weeks of IMT. The addition of IMT to standard training increased significantly the forced expiratory volume in the first second to vital capacity ratio (FEV1/VC), and the maximum voluntary ventilation $(M V V)(p<0.05)$ with changes of $5.7 \%$, and $28.6 \%$, respectively, in $M M A$ athletes. The kickboxing group showed no significant changes. The interaction of the sport discipline and IMT intervention yielded a strong significant change in the $\operatorname{MVV}(F(1,11)=14.53, p<0.01)$, and $F E V 1 / V C(F(1,11)=20.67, p<0.01)$ to the benefit of MMA athletes in comparison with kickboxing athletes. Combining resistive IMT for 6 weeks with standard training was effective to improve some pulmonary functions in MMA athletes, but did not lead to additional gains in kickboxing athletes.

Key words: resistance inspiratory muscle trainer, combat sports, spirometry, respiratory function, lung volumes.

\section{Introduction}

Proper breathing is an essential technique for athletes. Lung function tests are among those included in the measurement of an individual's fitness. It is estimated that people with higher levels of physical activity have higher vital capacity (VC) than less active people of the same age, gender, and body measures (Bakhtar et al., 2019; Rong et al., 2008). Physical activity and exercise improve VC, forced vital capacity (FVC), and maximum voluntary ventilation (MVV) in comparison with sedentary individuals (Atan et al., 2012; Durmic et al., 2017). The inspiratory muscle warm-up also improves pulmonary function markers (Özdal, 2016).

Several studies have been conducted to investigate and compare the ventilatory volumes in samples of elite athletes to determine the influence of different physical activities on the pulmonary function. Durmic et al. (2017) compared the pulmonary functions of endurance and power athletes $(n=470)$ and found that the FVC, FEV1, and VC in the endurance athletes' group were significantly higher than the measurements in both the power and control groups. This indicates that exercise may affect pulmonary function. Similarly, a study in Serbia of 1,639 athletes resulted in higher lung volumes for athletes participating in endurance sports activities in comparison with those in power and team sports (Lazovic-Popovic et al., 2015).

Mazic et al. (2015) conducted a large-scale study on 15 sports disciplines and sedentary individuals. The results showed that VC, FEV, and FVC in rowing, basketball, and water polo athletes were significantly higher than those of the

1 - Department of Biomedical Engineering, School of Applied Medical Sciences, The German Jordanian University, Amman, Jordan. 
control group. These differences were not recorded in other sports considered in the study, and the researchers suggested that the training type used in these sports could have potential for improving respiratory function.

Inspiratory muscle training (IMT) consists of a series of specific breathing and other exercises which aim to improve the function of respiratory muscles. IMT was used mainly in the field of pulmonary rehabilitation (Beaumont et al., 2015; Elbouhy et al., 2014), but recently found its way to athletes in various sports. However, the benefits of IMT for exercise performance and pulmonary function variables are highly controversial, and the results of previous research vary. HajGhanbari et al. (2013) in their review and meta-analysis based on 21 research studies, highlighted a significant positive influence of respiratory muscle training (RMT) on performance of some athletes and incremental increases in inspiratory muscle strength, endurance, and MVV in favor of IMT/RMT. Romer et al. (2003) further reported improvements in inspiratory muscle function measured by pressure and flow; however, they reported a small, but significant reduction in the inspiratory muscle function after a detraining period, as well as maintenance of the initial increase in function when IMT continued, even at lower training frequency. However, the review by Karsten et al. (2018) based on 25 papers reveled a significant improvement in sport performance and inspiratory muscle strength due to IMT with linear workload devices (IMT-linear), but with no influence on pulmonary function markers.

Studies of IMT influence on pulmonary function vary based on the sport type. In a study of fin-swimmers $(\mathrm{n}=20)$ a significant improvement was reported in performance based on the apnoe max test and in respiratory muscle strength, combined with improvements in the ventilatory variables, but these improvements were not statistically significant (Vašícková et al., 2017). IMT influence on pulmonary function in disabled swimmers showed a significant increase in ventilatory function and respiratory muscle strength (Okrzymowska et al., 2019). RożekPiechura et al. (2020) reported a significant improvement in most of the lung ventilation variables and respiratory muscle strength in longdistance runners after 8 weeks of IMT using a POWERbreathe device; however, using a
Threshold device, only the vital capacity improved significantly.

Mackala et al. (2019) investigated the IMT impact on performance of eight young soccer players and a control group of the same size, and the results showed positive significant impact on expiratory muscle strength and FVC over a period of 8 weeks. Lomax et al. (2011) reported increased performance and inspiratory muscle pressure in soccer players when combining the inspiratory muscle warm-up and IMT rather than considering each factor alone. In cyclists, enhanced performance was also reported after IMT, leading to faster simulated $40 \mathrm{~km}$ time trials by $4.6 \%$ in comparison with a placebo group (Romer et al., 2002).

IMT devices are widely used in training and have found their way into many research projects and training programs. They vary in their concept of work, mainly differing in their pressure threshold, endurance, and flow resistance (Menzes et al., 2018). In a study using pressure-threshold devices (Powerbreathe, UK), the investigated rowers' performance and inspiratory muscle strength improved significantly in comparison with a placebo group, revealing the importance of IMT in the studied group under the test conditions (Volianitis et al., 2001).

In a study using a resistive IMT device (Ultrabreathe lung trainer) intended to improve physical fitness of military and law enforcement personnel, the military force participants $(n=17)$ showed no significant differences in the pulmonary function tests and endurance performance after 6 weeks of intensive training (Sperlich et al., 2009).

Inspiratory muscle training results in strengthening the neck and upper chest muscles, also increasing the diaphragm's thickness after training, which has been reported to lead to the improved lung ventilation (Enright et al., 2004). Many studies have been conducted on IMT and its effect on respiratory function, as shown previously, and while some resulted in no changes in the pulmonary function, others yielded significant changes. However, most studies concentrated on endurance athletes, such as swimmers, rowers, and cyclists, while fewer investigations have been conducted so far on dynamic and combat sport athletes. Hence, this 
study investigated whether six weeks of IMT in addition to a standard training program would improve the pulmonary function of athletes in combat sports. The current study examined the effects of adding resistive IMT to standard training in two groups of elite mixed martial arts (MMA) and kickboxing athletes, and in an agematched control group. It assesses and compares measured ventilatory volumes (FVC), VC, forced expiratory volume in the first second (FEV1), peak expiratory flow (PEF), MVV, and FEV1/VC ratio.

\section{Methods}

\section{Participants}

A total of 28 male competitive athletes from two combat sports (14 kickboxers and 14 MMA athletes) were selected for this study. The recruitment was made from four clubs (two MMA and two kickboxing clubs) whose members participated in elite MMA and kickboxing matches. A systematic sampling approach from lists of members' names arranged alphabetically was chosen. The exclusion criteria were as follows: history of respiratory complaints or cardiopulmonary diseases, smoking (selfreported), use of medications during the test period, and less than 4 years of training experience or training break of more than 4 months within that period. Two of the MMA athletes were excluded because they did not meet the inclusion criteria. The included 26 athletes' average age was 22.7 years \pm 4.3 . None of the participants had experience with IMT prior to the experiment. Each of the two groups was further randomly divided equally into two subgroups (a control group (CG) performing the standard training program with no IMT and an experimental group (EG) additionally performing IMT on resistive IMT devices), with seven athletes for each of the kickboxing subgroups and six athletes for each of the MMA subgroups. The average age, body mass and height by group are shown in Table 1.

All participants received a full explanation of the experimental procedure and the required tests. The 26 athletes provided written informed consent before the experiment and were notified that they could withdraw from the study whenever they wished. All procedures were conducted in accordance with the Declaration of Helsinki. All the study procedures received ethical clearance (REC/2/2020) from the research ethics committee at the German-Jordanian University.

Measures

The tests were performed before the athletes' training sessions at their training site. All athletes were familiarized with the test procedure and were instructed not to eat for at least 2 hours before the testing session. The initial test was completed in September, when athletes were in their standard preparation phase for the upcoming spring/summer competition season, training five to six days per week. The same test was repeated after the 6 weeks of IMT for both control and experimental groups. The spirometry measurements were performed according to ATS/ERS recommendations (Miller et al., 2005), in a comfortable temperature between 18 and $23^{\circ} \mathrm{C}$, and with two-minute rest intervals between the test repetitions. Measurements were performed using the Pony FX, Class II, manufactured by COSMED, Italy. The system was calibrated before the test with a precision 3-L calibration syringe. The test was performed with participants holding the spirometer in one hand and the nose clip in place.

The following measurements were included and analyzed as absolute value and as the percentage of the predicted values: VC (l), FVC (l), FEV1 (l), PEF (1/s), and MVV (1/min). The predicted values were calculated based on gender, age, and body height (Quanjer et al., 1993).

\section{Inspiratory Muscle Training}

IMT was performed twice a day, seven days a week, for six weeks. The first training session was in the morning, between 7:00 and 9:30 a.m., and the second session was in the evening, around 7:00 p.m., and each session included 30 breaths. The commercially available Ultrabreathe resistance-based respiratory muscle trainer (Tangent Healthcare Ltd., UK) was used by the experimental group. Athletes were asked to maintain their standard training program and not to participate in any other physical activities during the study. The standard training program included training five to six sessions weekly. The first IMT sessions were done under supervision in the sport clubs where participants were members. Each participant was asked to inhale quickly and fully and then to exhale slowly and for a long period. The device was adjusted for each athlete 
individually by rotating the adjustment sleeve and increasing resistance until the participant was just able to finish the required 30 breaths in approximately 3 minutes, approaching maximum fatigue. Participants in the experimental group were asked to perform the remaining training sessions at home, to fill in a training diary to follow up, and to increase resistance on the device every few days, making sure they did not experience any discomfort or pain. Each athlete performed training on a personal device in a standing position.

During the six weeks, all participants in the EG and CG followed their standard training programs, and the study was conducted over a period free from any athletic competitions.

\section{Statistical Analysis}

The values measured in the test were described using the mean and standard deviation (SD), the comparison between particular groups was performed using an unpaired t-test, and the before and after measurements were compared using a paired t-test. All statistical tests used a two-sided $p$-value of 0.05 as a threshold for statistical significance. For the comparison between the different groups, a two-way analysis of variance (ANOVA) with repeated measures on one factor was used with two groups (experimental and control) and training effect (before and after IMT). The statistical toolbox in the MATLAB (2019) software was used for the evaluation.

\section{Results}

Comparison between MMA and Kickboxing Athletes before Intervention

The demographic and anthropometric data in Table 1 shows that MMA athletes had significantly higher body mass in comparison with kickboxing athletes $(p<0.05)$. However, no significant differences emerged for age, body height, and BMI between MMA and kickboxing athletes. Table 1 shows the results of the pulmonary function measurements (VC, FVC, FEV1, PEF, FEV1/VCx100, and MVV) in the two groups of kickboxing $(n=14)$ and MMA $(n=12)$ before the IMT sessions regardless of their subgroup as control or experimental. The VC and FVC in the MMA group $(5.30 \pm 0.42 \mathrm{~L}$ and $4.99 \pm$ $0.40 \mathrm{~L}$, respectively) were significantly higher $(p<$ $0.05)$ than in the kickboxing group $(4.98 \pm 0.30 \mathrm{~L}$ and $4.71 \pm 0.26 \mathrm{~L}$, respectively). When analyzing the differences in the pulmonary function measures between kickboxing and MMA athletes as a percentage of the predicted respiratory values, given that the predicted values used in the percentages were calculated based on gender, age, and body height of each athlete and using the formulas from Quanjer et al. (1993), no significant differences were noticed.

\section{Effect of IMT on Kickboxing Athletes}

The baseline characteristics of the kickboxing athletes can be seen in Table 2 . The age and anthropometric variables showed no significant differences between the experimental and control group $(p>0.05)$, which indicates their comparability.

Changes in the respiratory functional variables for kickboxing athletes can be seen in Table 3, along with the mean values and the corresponding standard deviations. A paired ttest was used for the comparison within each group before and after training. The $p$-values show that both the control and experimental groups had no significant changes after the training period.

A further comparison was done between the four groups of kickboxing athletes using a two-way ANOVA with repeated measures on one factor (the time effect factor) with training group (two levels, experimental and control) and time effect (two levels, before and after the IMT intervention). The results show a significant difference between the control and experimental groups in the MVV measure $(\mathrm{F}(1,12)=4.82, p=$ $0.049)$. The PEF measure increased significantly $(\mathrm{F}(1,12)=9.16, p=0.011)$ after the training period by $8.4 \%$. However, this change cannot be related to the IMT sessions alone since it occurred while considering both the control and experimental groups together.

\section{Effect of IMT on MMA Athletes}

Table 2 shows the baseline characteristics of MMA athletes. It was noticed that body height in the control group was significantly higher $(p<$ $0.05)$ than in the experimental group by $4.6 \%$. The age and the other anthropometric variables were comparable with no significant differences between the experimental and control group $(p>$ 0.05).

Table 4 shows MMA athletes' results before and after IMT. The control group showed no 
differences before and after the 6-week period of the experiment, and most of the readings were similar, with only small variations. A significant change was recorded in the experimental group for both the FEV1 $(p=0.038)$ and the FEV1/VC ratio $(p=0.044)$ after IMT. The changes were $4.2 \%$ in the FEV1 and $5.7 \%$ in the FEV1/VC ratio. The MVV showed a strongly significant $(p=0.005)$ increase $(28.6 \%)$ after training.

A further comparison was done between the four groups of MMA athletes using a two-way ANOVA with repeated measures on one factor with two training groups (experimental and control) and time effect (before and after the IMT intervention). The results show a significant difference $(9.3 \%)$ between the control and experimental groups in the FEV1 value $(\mathrm{F}(1,10)=$ 11.45, $p=0.003)$, and a significant difference $(6.6 \%)$ in the PEF value $(\mathrm{F}(1,10)=6.55, p=0.028)$ between the control and the experimental group. The FEV1/VC ratio and the MVV both changed significantly $(\mathrm{F}(1,10)=5.18, p=0.034$, and $\mathrm{F}(1,10)$ $=9.31, p=0.012$, respectively) due the interaction between the IMT intervention over the time and the two training groups.

\section{Effect of IMT on MMA Vs. Kickboxing Athletes}

Even though the previous comparisons showed changes in the pulmonary function within each sport discipline for both control and experimental groups, investigating the main effect of IMT intervention on the experimental kickboxing and MMA groups showed a significant increase $(4.6 \%)$ in the PEF values $(\mathrm{F}(1,11)=5.92, p=0.033)$, but no changes were noticed in the rest of the measured pulmonary functions. The effect of the sport discipline on the pulmonary function yielded significantly higher values for the VC, FVC, and FEV1 in the MMA experimental group in comparison with the kickboxing experimental group $((\mathrm{F}(1,11)=8.50, p$ $=0.014, \mathrm{~F}(1,11)=8.53, p=0.014$, and $\mathrm{F}(1,11)=5.54$, $p=0.038$, respectively); and the differences were $8.3 \%, 8.8 \%$, and $7.2 \%$, respectively. The interaction of the sport discipline and the IMT intervention yielded a strongly significant change in two variables, the $\operatorname{MVV}(F(1,11)=14.53, p<0.01)$, and FEV1/VC $(F(1,11)=20.67, p<0.01)$.

Table 1

Descriptive statistics for both groups of athletes and a comparison of respiratory variables as absolute values and as percentages of the predicted ones between kickboxing and MMA athletes before IMT.

\begin{tabular}{|c|c|c|c|c|c|c|c|}
\hline \multirow[b]{2}{*}{ Variable } & \multicolumn{3}{|c|}{ Kickboxing $(\mathrm{n}=14)$} & \multicolumn{3}{|c|}{ MMA (n=12) } & \multirow{2}{*}{$p$-value } \\
\hline & Mean & \pm & SD & Mean & \pm & SD & \\
\hline Age (years) & 22.9 & \pm & 5.5 & 22.6 & \pm & 2.0 & 0.871 \\
\hline Body mass (kg) & 67.9 & \pm & 8.6 & 76.9 & \pm & 8.4 & 0.013 \\
\hline Body height (cm) & 174.6 & \pm & 8.6 & 178.8 & \pm & 6.8 & 0.179 \\
\hline BMI $\left(\mathrm{kg} / \mathrm{m}^{2}\right)$ & 22.2 & \pm & 2.0 & 24.1 & \pm & 2.8 & 0.074 \\
\hline $\mathrm{VC}(\mathrm{L})$ & 4.98 & \pm & 0.30 & 5.30 & \pm & 0.42 & 0.034 \\
\hline $\mathrm{VC}(\%)$ & 88.42 & \pm & 9.61 & 94.54 & \pm & 7.10 & 0.880 \\
\hline $\mathrm{FVC}(\mathrm{L})$ & 4.71 & \pm & 0.26 & 4.99 & \pm & 0.40 & 0.047 \\
\hline FVC (\%) & 93.13 & \pm & 9.04 & 93.19 & \pm & 7.32 & 0.984 \\
\hline FEV1 (L) & 4.34 & \pm & 0.19 & 4.45 & \pm & 0.44 & 0.435 \\
\hline FEV1 (\%) & 100.55 & \pm & 6.35 & 98.06 & \pm & 9.17 & 0.423 \\
\hline FEV1/VC & 87.44 & \pm & 5.51 & 83.92 & \pm & 4.70 & 0.095 \\
\hline FEV1/VC (\%) & 108.21 & \pm & 6.59 & 105.34 & \pm & 7.04 & 0.295 \\
\hline PEF (L/s) & 10.32 & \pm & 0.52 & 10.58 & \pm & 0.57 & 0.236 \\
\hline PEF (\%) & 104.91 & \pm & 7.57 & 104.30 & \pm & 5.36 & 0.817 \\
\hline MVV (L/min) & 146.19 & \pm & 20.98 & 130.47 & \pm & 21.14 & 0.070 \\
\hline MVV (\%) & 105.43 & \pm & 20.51 & 89.26 & \pm & 19.99 & 0.054 \\
\hline
\end{tabular}

Abbreviations: BMI-body mass index, VC-vital capacity, FVC-forced vital capacity,

FEV1-forced expiratory volume in the first second, PEF-peak expiratory flow rate, MVV-maximal voluntary ventilation. 
Table 2

Descriptive statistics for kickboxing and MMA experimental and control groups.

\begin{tabular}{|c|c|c|c|c|c|c|}
\hline \multirow[t]{2}{*}{ Athletes } & \multicolumn{2}{|c|}{ Kickboxing $(\mathrm{n}=14)$} & \multirow[t]{2}{*}{$p$-value } & \multicolumn{2}{|c|}{ MMA $(n=12)$} & \multirow[t]{2}{*}{$p$-value } \\
\hline & $\mathrm{EG}(\mathrm{n}=7)$ & $\mathrm{CG}(\mathrm{n}=7)$ & & $\mathrm{EG}(\mathrm{n}=6)$ & CG $(n=6)$ & \\
\hline Variable & Mean \pm SD & Mean \pm SD & & Mean \pm SD & Mean \pm SD & \\
\hline Age (years) & $22.3 \pm 7.4$ & $23.4 \pm 3.1$ & 0.715 & $23.0 \pm 3.0$ & $22.2 \pm 2.7$ & 0.623 \\
\hline Body mass (kg) & $66.6 \pm 10.8$ & $69.3 \pm 6.3$ & 0.579 & $74.0 \pm 10.6$ & $79.8 \pm 4.7$ & 0.257 \\
\hline Body height $(\mathrm{cm})$ & $172.0 \pm 9.8$ & $177.3 \pm 6.8$ & 0.268 & $174.8 \pm 7.4$ & $182.8 \pm 3.2$ & 0.045 \\
\hline BMI $\left(\mathrm{kg} / \mathrm{m}^{2}\right)$ & $22.4 \pm 2.5$ & $22.0 \pm 1.3$ & 0.719 & $24.3 \pm 4.2$ & $23.9 \pm 0.7$ & 0.812 \\
\hline
\end{tabular}

Abbreviations: $B M I$, body mass index; $E G$, experimental group; $C G$, control group.

Table 3

Comparison of pairs for changes in ventilatory variables pre- and post-training in the control and experimental groups of kickboxing athletes.

\begin{tabular}{|c|c|c|c|c|c|c|}
\hline \multirow[t]{3}{*}{ Variable } & \multicolumn{3}{|c|}{ Control Group $(\mathrm{n}=7)$} & \multicolumn{3}{|c|}{ Experimental Group $(\mathrm{n}=7)$} \\
\hline & Pre & Post & $p$-value & Pre & Post & $p$-value \\
\hline & $\begin{array}{c}\text { Mean } \pm \text { SD } \\
\quad(C V \%)\end{array}$ & $\begin{array}{c}\text { Mean } \pm \text { SD } \\
(C V \%)\end{array}$ & & $\begin{array}{c}\text { Mean } \pm \text { SD } \\
(C V \%)\end{array}$ & $\begin{array}{c}\text { Mean } \pm \text { SD } \\
(C V \%)\end{array}$ & \\
\hline $\mathrm{VC}(\mathrm{L})$ & $\begin{array}{c}5.04 \pm 0.39 \\
(7.7 \%)\end{array}$ & $\begin{array}{c}5.09 \pm 0.18 \\
(3.5 \%)\end{array}$ & 0.778 & $\begin{array}{c}4.91 \pm 0.16 \\
\quad(3.3 \%)\end{array}$ & $\begin{array}{c}4.97 \pm 0.63 \\
(12.7 \%)\end{array}$ & 0.846 \\
\hline FVC (L) & $\begin{array}{c}4.76 \pm 0.37 \\
(7.8 \%)\end{array}$ & $\begin{array}{c}4.83 \pm 0.17 \\
\quad(3.5 \%)\end{array}$ & 0.611 & $\begin{array}{c}4.67 \pm 0.10 \\
(2.1 \%)\end{array}$ & $\begin{array}{c}4.68 \pm 0.60 \\
(12.8 \%)\end{array}$ & 0.965 \\
\hline FEV1 (L) & $\begin{array}{l}4.29 \pm 0.15 \\
\quad(3.5 \%)\end{array}$ & $\begin{array}{c}4.30 \pm 0.31 \\
(7.2 \%)\end{array}$ & 0.901 & $\begin{array}{c}4.40 \pm 0.22 \\
\quad(5.0 \%)\end{array}$ & $\begin{array}{c}4.14 \pm 0.55 \\
(13.3 \%)\end{array}$ & 0.284 \\
\hline FEV1/VC & $\begin{array}{c}85.34 \pm 5.60 \\
(6.6 \%)\end{array}$ & $\begin{array}{c}84.55 \pm 5.60 \\
(6.6 \%)\end{array}$ & 0.655 & $\begin{array}{c}89.54 \pm 4.92 \\
\quad(5.5 \%)\end{array}$ & $\begin{array}{c}83.18 \pm 3.69 \\
(4.4 \%)\end{array}$ & 0.063 \\
\hline PEF (L/s) & $\begin{array}{c}10.50 \pm 0.48 \\
(4.6 \%)\end{array}$ & $\begin{array}{c}11.54 \pm 1.41 \\
(12.2 \%)\end{array}$ & 0.059 & $\begin{array}{c}10.13 \pm 0.53 \\
(5.2 \%)\end{array}$ & $\begin{array}{c}10.82 \pm 0.65 \\
(6.0 \%)\end{array}$ & 0.101 \\
\hline MVV (L) & $\begin{array}{c}135.26 \pm 12.85 \\
(9.5 \%)\end{array}$ & $\begin{array}{c}131.93 \pm 15.20 \\
(11.5 \%)\end{array}$ & 0.742 & $\begin{array}{c}157.13 \pm 22.57 \\
(14.4 \%)\end{array}$ & $\begin{array}{c}139.26 \pm 22.09 \\
(15.9 \%)\end{array}$ & 0.165 \\
\hline
\end{tabular}

Abbreviations: VC-vital capacity, FVC-forced vital capacity,

FEV1-forced expiratory volume in the first second, PEF-peak expiratory flow rate,

$M V V$-maximal voluntary ventilation, $C V$-coefficient of variation. 
Table 4

Comparison of pairs for changes in ventilatory variables pre-and post-training in the control and experimental groups of $M M A$ athletes.

\begin{tabular}{|c|c|c|c|c|c|c|}
\hline \multirow[t]{3}{*}{ Variable } & \multicolumn{3}{|c|}{ Control Group (n=6) } & \multicolumn{3}{|c|}{ Experimental Group $(\mathrm{n}=6)$} \\
\hline & Pre & Post & $p$-value & Pre & Post & $p$-value \\
\hline & $\begin{array}{c}\text { Mean } \pm \text { SD } \\
(\mathrm{CV} \%)\end{array}$ & $\begin{array}{c}\text { Mean } \pm \text { SD } \\
\quad(C V \%)\end{array}$ & & $\begin{array}{c}\text { Mean } \pm \text { SD } \\
\quad(\mathrm{CV} \%)\end{array}$ & $\begin{array}{c}\text { Mean } \pm \text { SD } \\
\quad(\mathrm{CV} \%)\end{array}$ & \\
\hline $\mathrm{VC}(\mathrm{L})$ & $\begin{array}{c}5.15 \pm 0.54 \\
(10.5 \%)\end{array}$ & $\begin{array}{c}5.14 \pm 0.20 \\
(3.9 \%)\end{array}$ & 0.949 & $\begin{array}{c}5.44 \pm 0.23 \\
(4.2 \%)\end{array}$ & $\begin{array}{c}5.36 \pm 0.27 \\
(5.0 \%)\end{array}$ & 0.225 \\
\hline FVC (L) & $\begin{array}{c}4.90 \pm 0.53 \\
(10.8 \%)\end{array}$ & $\begin{array}{c}4.79 \pm 0.23 \\
(4.8 \%)\end{array}$ & 0.698 & $\begin{array}{c}5.08 \pm 0.25 \\
\quad(4.9 \%)\end{array}$ & $\begin{array}{c}5.15 \pm 0.17 \\
(3.3 \%)\end{array}$ & 0.247 \\
\hline FEV1 (L) & $\begin{array}{c}4.25 \pm 0.53 \\
(12.5 \%)\end{array}$ & $\begin{array}{c}4.09 \pm 0.20 \\
(4.9 \%)\end{array}$ & 0.436 & $\begin{array}{c}4.51 \pm 0.23 \\
(5.1 \%)\end{array}$ & $\begin{array}{c}4.70 \pm 0.16 \\
(3.4 \%)\end{array}$ & 0.038 \\
\hline FEV1/VC & $\begin{array}{c}82.52 \pm 5.77 \\
(7.0 \%)\end{array}$ & $\begin{array}{c}79.63 \pm 3.02 \\
\quad(3.8 \%)\end{array}$ & 0.280 & $\begin{array}{c}82.94 \pm 4.64 \\
\quad(5.6 \%)\end{array}$ & $\begin{array}{c}87.69 \pm 1.94 \\
(2.2 \%)\end{array}$ & 0.044 \\
\hline PEF (L/s) & $\begin{array}{c}10.28 \pm 0.56 \\
\quad(5.4 \%)\end{array}$ & $\begin{array}{c}10.22 \pm 1.13 \\
(11.1 \%)\end{array}$ & 0.915 & $\begin{array}{c}10.85 \pm 0.42 \\
(3.9 \%)\end{array}$ & $\begin{array}{c}11.08 \pm 0.51 \\
(4.6 \%)\end{array}$ & 0.081 \\
\hline MVV (L) & $\begin{array}{c}135.15 \pm 28.72 \\
(21.3 \%)\end{array}$ & $\begin{array}{c}126.32 \pm 23.11 \\
(18.3 \%)\end{array}$ & 0.514 & $\begin{array}{c}125.78 \pm 10.28 \\
(8.2 \%)\end{array}$ & $\begin{array}{c}161.72 \pm 9.50 \\
(5.9 \%)\end{array}$ & 0.005 \\
\hline
\end{tabular}

Abbreviations: VC-vital capacity; $F V C$-forced vital capacity;

FEV1-forced expiratory volume in the first second; PEF-peak expiratory flow;

$M V V$-maximal voluntary ventilation, $C V$-coefficient of variation.

\section{Discussion}

Researchers have already investigated the pulmonary function in athletes from various disciplines. To our knowledge, this study was the first to investigate IMT effects on pulmonary function in combat sports, specifically kickboxing and MMA. Notably, in this study, the measured values of VC and FVC in kickboxing were lower than the corresponding estimated values based on body height and age and calculated using the ERS formulas. In MMA athletes, besides the VC and the FVC, the MVV was also lower than the estimated values. This has been observed in other studies for dynamic sports athletes such as boxers (Mazic et al., 2015), and power athletes (Durmic et al., 2017). Therefore, it may be concluded that standard exercises used in kickboxing and MMA training programs do not support pulmonary function markers, and adapting exercises from other sport disciplines, such as swimming, water polo, and rowing, may help improve respiratory function (Lazovic-Popovic et al., 2015; Mazic et al., 2015; Okrzymowska et al., 2019).

A comparison between MMA and kickboxing before IMT training shows no significant difference between the two sports when considering the results as percentages of the estimated values. Ermis et al. (2019) compared 
practitioners of four martial arts (judo, Muay Thai, boxing, and Taekwondo) and found no significant difference in the measured pulmonary functions in their sample $(n=58)$.

The training period was set at six weeks, as this was the period of highest improvements reported by Romer et al. (2003). The post-training results differed between the two experimental groups; but the two control groups showed no significant changes after the six weeks. The VC and FVC were lower than the estimated levels for both groups of athletes (kickboxing and MMA) and showed no significant change after training. This might be explained by the fact that the FVC and the VC reflect individual lung size and further growth in adults who already reached their optimized lung function is limited (Plavsic et al., 2011). In a study conducted by Sherrill et al. (1989) on 1,024 subjects, they reported that lung function stopped increasing by the age of 19.8 years in males, indicating limited further growth in adults after that average age. The effect of the interaction between the sport disciplines and the six weeks of IMT within the two MMA and kickboxing experimental groups showed a significant effect in favor of MMA athletes for the pulmonary functions FEV1/VC and MVV. However, no significant changes were recorded in the rest of the functions. These results indicate an effect of the sport discipline on the efficiency of IMT, however, a generalization of this indication needs further investigation on a larger group of athletes.

Kickboxing athletes also showed no significant changes in their pulmonary function markers (FEV1, PEF, and MVV). The study on the interaction between the IMT time factor and the two experimental and control groups of kickboxing athletes confirmed the paired test findings providing no significant effect of IMT on the measured functions. Similar results were reported in some studies for other sport disciplines (Romer et al., 2003; Sperlich et al., 2009; Volianitis et al., 2001). This might be explained by the fact that the measured basic pulmonary function variables in kickboxing athletes before training were close to or above $100 \%$ of the estimated standard limits based on age and body height. In a study by Okrzymowska et al. (2019) performed with disabled swimmers (n $=16$ ), all the measured pulmonary functions increased significantly after IMT, but by the beginning of the study, the basic variables were lower than the estimated normal values $(70-80 \%$ of the standard ones), which may explain the existence of a capacity for improvement, which may not be the case for kickboxing athletes in this study.

Considering MMA athletes, significant improvements were recorded in the FEV1 and MVV pulmonary function markers and the FEV1/VC ratio $(p<0.05)$. This is in contradiction with the kickboxing athletes' results in this study and with the research conducted by Sperlich et al. (2009) using the same Ultrabreathe resistive lung training device. In that study, none of the measured pulmonary function markers changed significantly, and no significant improvement in performance was recorded. The study on the interaction between the IMT time effect and the two experimental and control groups of MMA athletes confirmed the paired test findings providing significant effect of IMT in favor of the experimental group for two measures, i.e., MVV and FEV1/VC. However, some studies showed improvement in FEV1 after IMT (Mackala et al., 2019). Koc and Saritas (2019) reported a significant increase in FEV1 and MVV values after IMT in favor of the experimental group, with $p<0.05$. Hajghanbari et al. (2013), in a review of 21 papers, also reported significant increment in FEV1 and MVV after IMT and no significant change in FVC. In this study, the MVV values of MMA athletes before IMT were lower than the standard values, and thus, space for improvement exists (Okrzymowska et al., 2019).

Even though the PEF is an important marker of expiratory muscle strength, it showed no changes in both type of sports and in both control and experimental groups. Similar results were reported by Mackala et al. (2019). Differences in the motivation of athletes participating in the study might also account for the results of the study; this was also reported by Volianitis et al. (2001).

\section{Study Limitations}

There are some limitations of this study which should be acknowledged. The study included only 26 male athletes; further investigation on a larger sample and with both genders could provide more specific results and enable the generalization of the study results. 
Further investigation on the long-term effect of IMT on pulmonary function after stopping training can better help determine the reversibility of training and the training capacity needed to maintain the improvement (Romer et al., 2003). Investigating other pulmonary function variables, such as maximum inspiratory and maximum expiratory pressure, and performance of athletes would better support the study, given the number of studies which have reported improvements in performance and/or maximum inspiratory pressure, although no significant changes in the pulmonary function markers were reported (Vašícková et al., 2017; Volianitis et al., 2001).

The Ultrabreathe system used in this study is a resistance-based trainer with a sleeve to adjust resistance based on the user's capacity to achieve 30 breaths with no scale to show the actual resistance. This may influence the results based on the athletes' own judgment and their motivation while performing the exercises.

\section{Conclusions}

In conclusion, at the beginning of the six weeks of intervention, MMA and kickboxing athletes showed no difference in their measured pulmonary function. The 6-week resistive IMT increased significantly the pulmonary function variables (FEV1, MVV, and FEV1/VC) in MMA athletes, but did not improve any variable in kickboxing athletes. When investigating the effect of interaction between IMT and sport discipline, the results yielded significant changes in two variables: MVV and FEV1/VC in MMA athletes in comparison with kickboxing athletes. Indicating that the benefits of IMT were related to the type of sport within our sample means it can be a good exercise for some athletes and some sports. Also, changes in the MMA athletes' measurements yielded significant differences due the effect of the interaction between the training factor and the discipline factor. However, evaluation of IMT feedback on the pulmonary function is complex, and these results need further investigation on a larger sample and for longer periods to generalize the results and understand the mechanism behind these changes. Considering the few studies investigating the pulmonary function in combat sports and, to our knowledge, no studies considering IMT in kickboxing and MMA, it is believed that this study will contribute to the literature in the field.

\section{Acknowledgements}

The authors thank the German-Jordanian University for its support in conducting this study using the laboratory devices. We would like to thank the athletes for the participation in this study.

\section{References}

Atan, T., Akyol, P., \& Çebi, M. (2013). Comparison of respiratory functions of athletes engaged in different individual sports branches. Dicle Medical Journal, 40(2), 192-198. https://doi.org/10.5798/diclemedj.0921.2013.02.0253

Bakhtar, F, Ahmad, Aminisani, N, Gilani, N. (2019). Psychological, social, and environmental predictors of physical activity among older adults: The socio-ecological approach using structural equation modeling analysis. Baltic Journal of Health and Physical Activity, 11(2), 117-126. https://doi:10.29359/BJHPA.11.2.12

Beaumont, M., Mialon, P., Ber-Moy, C. L., Lochon, C., Péran, L., Pichon, R., Gut-Gobert, C., Leroyer, C., Morelot-Panzini, C., \& Couturaud, F. (2015). Inspiratory muscle training during pulmonary rehabilitation in chronic obstructive pulmonary disease. Chronic Respiratory Disease, 12(4), 305-312. https://doi.org/10.1177/1479972315594625

Durmic, T., Lazovic Popovic, B., Zlatkovic Svenda, M., Djelic, M., Zugic, V., Gavrilovic, T., Mihailovic, Z., Zdravkovic, M., \& Leischik, R. (2017). The training type influence on male elite athletes' ventilatory function. BMJ Open Sport \& Exercise Medicine, 3(1). https://doi.org/10.1136/bmjsem-2017-000240

Elbouhy, M. S., AbdelHalim, H. A., \& Hashem, A. M. A. (2014). Effect of respiratory muscles training in weaning of mechanically ventilated COPD patients. Egyptian Journal of Chest Diseases and Tuberculosis, 63(3), 679-687. https://doi.org/10.1016/j.ejcdt.2014.03.008

Enright, S., Chatham, K., Ionescu, A. A., Unnithan, V. B., \& Shale, D. J. (2004). Inspiratory muscle training improves lung function and exercise capacity in adults with cystic fibrosis. Chest, 126(2), 405-411. https://doi.org/10.1378/chest.126.2.405 
Ermiş, E., Yılmaz, A. K., \& Mayda, M. H. (2019). Analysis of Respiratory Functions and Respiratory Muscle Strength of Martial Arts Athletes. International Journal of Applied Exercise Physiology, 8(1), 10-17. https://doi.org/10.30472/ijaep.v8i1.328

HajGhanbari, B., Yamabayashi, C., Buna, T. R., Coelho, J. D., Freedman, K. D., Morton, T. A., Palmer, S. A., Toy, M. A., Walsh, C., Sheel, A. W., \& Reid, W. D. (2013). Effects of respiratory muscle training on performance in athletes. Journal of Strength and Conditioning Research, 27(6), 1643-1663. https://doi.org/10.1519/jsc.0b013e318269f73f

Karsten, M., Ribeiro, G. S., Esquivel, M. S., \& Matte, D. L. (2018). The effects of inspiratory muscle training with linear workload devices on the sports performance and cardiopulmonary function of athletes: A systematic review and meta-analysis. Physical Therapy in Sport, 34, 92-104. https://doi.org/10.1016/j.ptsp.2018.09.004

Koç, M., \& Saritaş, N. (2019). The effect of respiratory muscle training on aerobic and anaerobic strength in adolescent taekwondo athletes. Journal of Education and Training Studies, 7(2), 103. https://doi.org/10.11114/jets.v7i2.3764

Lazovic, B., Mazic, S., Suzic-Lazic, J., Djelic, M., Djordjevic-Saranovic, S., Durmic, T., Zikic, D., \& Zugic, V. (2015). Respiratory adaptations in different types of sport. European Review for Medical and Pharmacological Sciences, 19(12), 2269-2274.

Lomax, M., Grant, I., \& Corbett, J. (2011). Inspiratory muscle warm-up and inspiratory muscle training: Separate and combined effects on intermittent running to exhaustion. Journal of Sports Sciences, 29(6), 563-569. https://doi.org/10.1080/02640414.2010.543911

Mackała, K., Kurzaj, M., Okrzymowska, P., Stodółka, J., Coh, M., \& Rożek-Piechura, K. (2019). The effect of respiratory muscle training on the pulmonary function, lung ventilation, and endurance performance of young soccer players. International Journal of Environmental Research and Public Health, 17(1), 234. https://doi.org/10.3390/ijerph17010234

Mazic, S., Lazovic, B., Djelic, M., Suzic-Lazic, J., Djordjevic-Saranovic, S., Durmic, T., Soldatovic, I., Zikic, D., Gluvic, Z., \& Zugic, V. (2015). Respiratory parameters in elite athletes - does sport have an influence? Revista Portuguesa De Pneumologia (English Edition), 21(4), 192-197. https://doi.org/10.1016/j.rppnen.2014.12.003

Menzes, K. K. P., Nascimento, L. R., Avelino, P. R., Polese, J. C., \& Salmela, L. F. T. (2018). A review on respiratory muscle training devices. Journal of Pulmonary \& Respiratory Medicine, 08(02). https://doi.org/10.4172/2161-105x.1000451

Miller, M. R., Crapo, R., Hankinson, J., Brusasco, V., Burgos, F., Casaburi, R., Coates, A., Enright, P., van der Grinten, C. P. M., Gustafsson, P., Jensen, R., Johnson, D. C., MacIntyre, N., McKay, R., Navajas, D., Pedersen, O. F., Pellegrino, R., Viegi, G., \& Wanger, J. (2005). General considerations for lung function testing. European Respiratory Journal, 26(1), 153-161. https://doi.org/10.1183/09031936.05.00034505

Okrzymowska, P., Kurzaj, M., Seidel, W., \& Rożek-Piechura, K. (2019). Eight weeks of inspiratory muscle training improves pulmonary function in disabled swimmers-a randomized trial. International Journal of Environmental Research and Public Health, 16(10), 1747. https://doi.org/10.3390/ijerph16101747

Özdal, M. (2016). Acute effects of inspiratory muscle warm-up on pulmonary function in healthy subjects. Respiratory Physiology \& Neurobiology, 227, 23-26. https://doi.org/10.1016/j.resp.2016.02.006

Plavsic, J., Djordjevic-Saranovic, S., Gavrilovic, T., Zlatkovic, J., \& Mazic, S. (2011). Respiratory parameters of elite national water polo and volleyball players. British Journal of Sports Medicine, 45(6), 539-539. https://doi.org/10.1136/bjsm.2011.084558.18

Quanjer, P. H., Tammeling, G. J., Cotes, J. E., Pedersen, O. F., Peslin, R., \& Yernault, J.-C. (1993). Lung volumes and forced ventilatory flows. European Respiratory Journal, 6(Suppl 16), 5-40. https://doi.org/10.1183/09041950.005s1693

Romer, L. M., McConnell, A. K., \& Jones, D. A. (2002). Effects of inspiratory muscle training on time-trial performance in trained cyclists. Journal of Sports Sciences, 20(7), 547-590. https://doi.org/10.1080/026404102760000053

Romer, L. M., \& McConnell, A. K. (2003). Specificity and reversibility of inspiratory muscle training. Medicine $\mathcal{E}$ Science in Sports \& Exercise, 35(2), 237-244. https://doi.org/10.1249/01.mss.0000048642.58419.1e 
Rong, C., Bei, H., Yun, M., Yuzhu, W., \& Mingwu, Z. (2008). Lung function and cytokine levels in professional athletes. Journal of Asthma, 45(4), 343-348. https://doi.org/10.1080/02770900801956371

Rożek-Piechura, K., Kurzaj, M., Okrzymowska, P., Kucharski, W., Stodółka, J., \&amp; Maćkała, K. (2020). Influence of inspiratory muscle training of various intensities on the physical performance of longdistance runners. Journal of Human Kinetics, 75(1), 127-137. https://doi.org/10.2478/hukin-2020-0031

Sherrill, D. L., Camilli, A., \& Lebowitz, M. D. (1989). On the temporal relationships between lung function and somatic growth. American Review of Respiratory Disease, 140(3), 638-644. https://doi.org/10.1164/ajrccm/140.3.638

Sperlich, PhD, B., Fricke, H., de Marées, M., Linville, J. W., \& Mester, J. (2009). Does respiratory muscle training increase physical performance? Military Medicine, 174(9), 977-982. https://doi.org/10.7205/milmed-d-04-6408

Vašíčková, J., Neumannová, K., \& Svozil, Z. (2017). The Effect of Respiratory Muscle Training on FinSwimmers' Performance. Journal of sports science \& medicine, 16(4), 521-526.

Volianitis, S., McConnell, A. K., Koutedakis, Y., McNaughton, L., Backx, K., \& Jones, D. (2001). Inspiratory muscle training improves rowing performance. Medicine and Science in Sports and Exercise, 33, 803-809. https://doi.org/10.1097/00005768-200105000-00020

\section{Corresponding author:}

\section{Nasim George Alnuman, PhD}

Department of Biomedical Engineering, School of Applied Medical Sciences, The German-Jordanian University, P. O. Box: 35247, Amman 11180, Jordan,

Tel.: +962-777-809309; Tel./Fax: +962-6-4294406

E-mail: nasim.alnuman@gju.edu.jo 